\title{
Electrophoretic Characterization of Lactic Dehydrogenases in the Genus Lactobacillus
}

\author{
By F. GASSER* \\ Department of Bacteriology and Immunology, University of California, \\ Berkeley, California 94720, U.S.A.
}

(Accepted for publication 30 April 1970)

\begin{abstract}
SUMMARY
Crude extracts of I46 strains of different species of Lactobacillus have been submitted to starch gel electrophoresis and the gels developed specifically for lactic dehydrogenases, D or L, NAD-dependent or NAD-independent. Each species contained at least one NAD-dependent lactic dehydrogenase specific for $\mathrm{D}(-)$ or for $\mathrm{L}(+)$ lactic acid; some species contained both enzymes. For each species there was a strict correlation between the stereospecificity of the NAD-dependent lactic dehydrogenases found in extracts and the type of lactic acid produced during growth, i.e. $\mathrm{D}(-), \mathrm{L}(+)$ or DL. The L-lactic dehydrogenases (NAD-dependent) of Lactobacillus casei and $L$. ferment $i$ were not reversible and consequently could not be detected after electrophoresis. Only those NAD-independent lactic dehydrogenases able to reduce phenazine methosulphate could be detected by the method of development used. Such enzymes were found in extracts of some homofermentative lactobacilli.

The number and the nature of the lactic dehydrogenases and their respective electrophoretic mobilities are constant within a species. Therefore the electrophoretic migration of lactic dehydrogenases of lactobacilli is a useful taxonomic marker for species differentiation.
\end{abstract}

\section{INTRODUCTION}

The widely accepted classification of rod-shaped lactic acid bacteria (genus Lactobacillus) given by Rogosa \& Sharpe (1959) is largely based on the work of Orla Jensen (1919). This author was the first to recognize that lactic acid bacteria can be divided into two subgroups in terms of the fermentative products formed from glucose. Following the terminology proposed later by Kluyver (1935), these are now known as the homo- and heterofermentative groups of lactobacilli. The former produce almost exclusively lactic acid from glucose; the latter produce equimolar quantities of lactic acid, ethanol and $\mathrm{CO}_{2}$. In conjunction with certain other physiological and nutritional characters, the mode of glucose fermentation was used by Orla Jensen to divide the rod-shaped lactic acid bacteria into three genera commonly regarded today as subgenera of Lactobacillus:

I. Thermobacterium. Homofermentative; do not ferment pentoses; grow at $45^{\circ}$ but not at $15^{\circ}$.

2. Stroptobacterium. Homofermentative; some ferment pentoses; grow poorly or not at all at $45^{\circ}$, but can grow at $15^{\circ}$.

* Permanent address: Institut Pasteur, 25 rue du Docteur Roux, Paris (XV), France. 


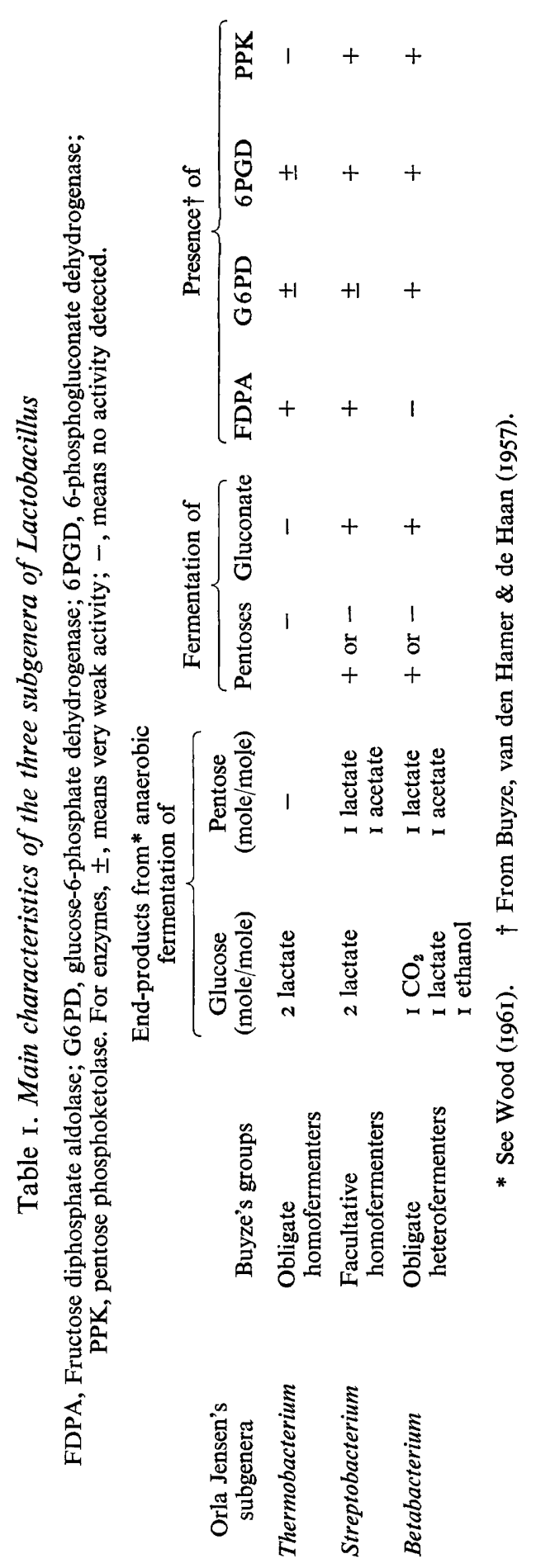


3. Betabacterium. Heterofermentative; some ferment pentoses; temperature range varies with species.

The full significance of the differences in glucose fermentation products among lactobacilli became evident only as a result of later biochemical studies, which showed that homofermentative species dissimilate glucose via the Embden-Meyerhof (EM) pathway, whereas heterofermentative species dissimilate this sugar via the hexose monophosphate (HMP) pathway (see Wood, I96I).

Buyze, van den Hamer \& de Haan (1957) showed that in terms of fermentative mechanisms, lactic acid bacteria can be divided into three distinct subgroups:

I. Obligately homofermentative species, which either lack completely or contain very low activities of two key enzymes of the HMP pathway, i.e. glucose-6-phosphate (G6P) dehydrogenase and 6-phosphogluconate (6PG) dehydrogenase, but contain a high activity of fructose diphosphate (FDP) aldolase; they are unable to ferment gluconic acid or pentoses.

2. Obligately heterofermentative species, which do not contain FDP aldolase, but have high activities of G6P and 6PG dehydrogenases. They ferment gluconic acid with $\mathrm{CO}_{2}$ production and pentoses with formation of lactic and acetic acids.

3. Facultatively heterofermentative species, which contain high levels of FDP aldolase, G6P and 6PG dehydrogenases. They ferment glucose exclusively by the EM pathway, but can also ferment gluconic acid and pentoses in the same fashion as species of group 2.

These three biochemical groups in fact correspond to the three subgenera of Orla Jensen (Table I).

The speciation of the lactobacilli was first systematically studied by Orla Jensen (I919). The species that he proposed, which were distinguished primarily by differences in the ranges of sugars fermented and in the optical configuration of the lactic acid formed, are still largely accepted today, although some changes in nomenclature have been necessary as a result of Orla Jensen's deliberate failure to observe the rules of priority. The delineation of these species was extended by Rogosa \& Sharpe (I959), who added valuable information concerning temperature ranges for growth, vitamin requirements and immunological relationships. The properties of the species of Lactobacillus accepted at present, as defined primarily through the work of Orla Jensen (1919) and Rogosa \& Sharpe (1959), are outlined in Tables 2 and 3.

Despite the seemingly satisfactory speciation of the group, it is not possible to assign all newly isolated Lactobacillus strains to a particular species, largely because of the variability with respect to the range of sugars fermented. Strains with properties intermediate between those characteristic of certain pairs of species are not uncommonly encountered. The mean base composition of the DNA of species of Lactobacillus covers a rather wide range (about 35 to 53 moles \% G+C; Gasser \& Sebald, I966; Gasser \& Mandel, I968; Tables 2, 3). Furthermore, the differences with respect to this property are not well correlated with a tripartite generic subdivision of the group in terms of biochemical and physiological properties: both the subgenera Thermobacterium and Betabacterium contain species of widely different $\mathrm{G}+\mathrm{C}$ content.

We have now undertaken a systematic comparative study of the properties of certain enzymes common to all members of the genus. The lactic dehydrogenases were selected, since the conversion of pyruvic to lactic acid is a reaction performed by all members of the group and plays an essential role in their energy-yielding 


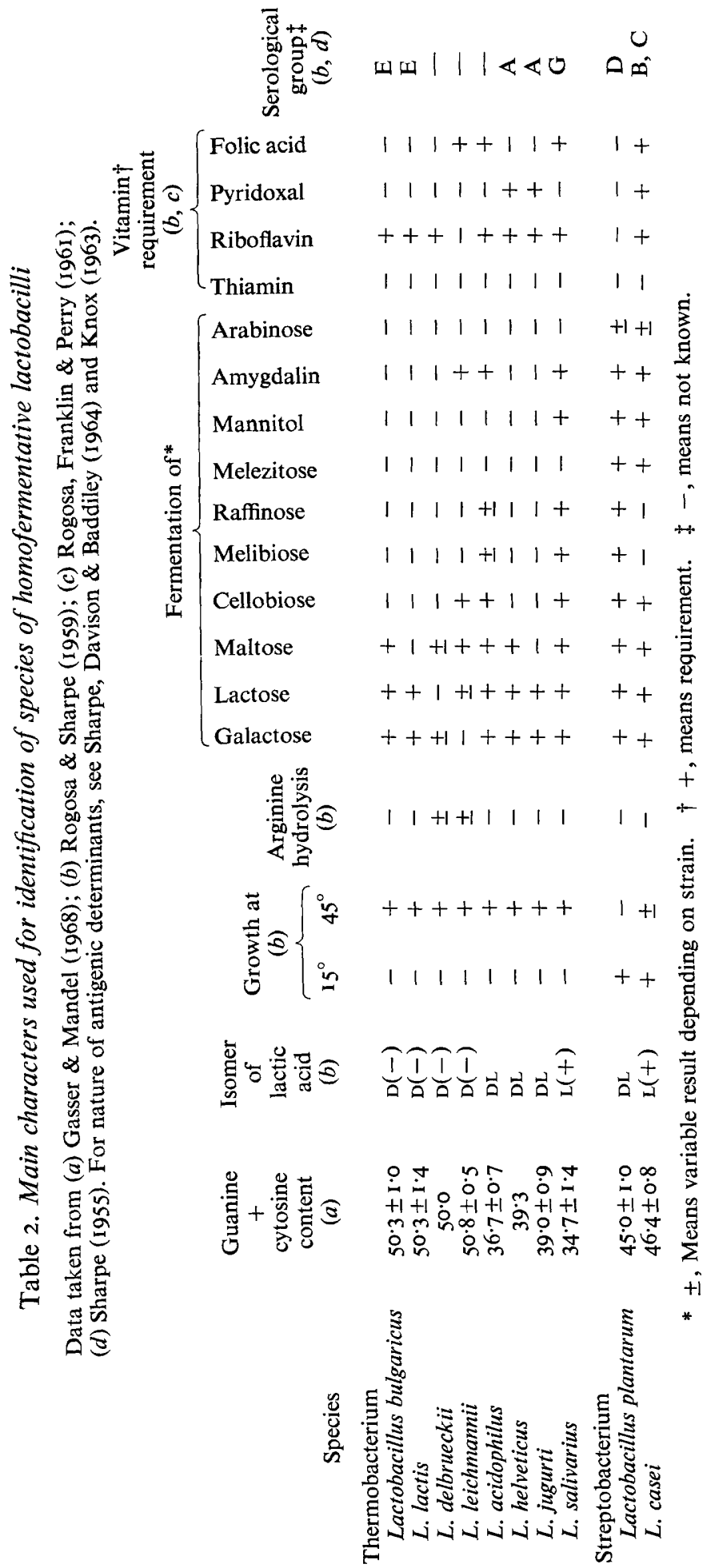


metabolism. Lactobacillus species can form either $\mathrm{D}(-)$ or $\mathrm{L}(+)$ lactic acid, or a racemic mixture. The formation of racemic lactic acid could involve either the combined action of a stereospecific lactic dehydrogenase and a lactic acid racemase, or the action of two different stereospecific lactic dehydrogenases. In Lactobacillus plantarum, one of the species which forms racemic lactic acid, Dennis \& Kaplan (1960) have shown conclusively that there are two stereospecific, nicotinamide adenine dinucleotide (NAD)-dependent lactic dehydrogenases distinguishable by molecular weight and by catalytic and immunological properties. This work accordingly suggests that the optical configuration of the lactic acid formed by a given species is determined by the possession of either one or two stereospecific, NAD-dependent lactic dehydrogenases.

\section{Table 3. Main characters of heterofermentative lactobacilli}

The ranges of carbohydrates fermented have not been included since most of these reactions are reported as variables in the tables of Rogosa \& Sharpe (I959). This may be due in part to the poorly known relationship of bacteria of this group with oxygen; some substrates are dissimilated under strict anaerobic conditions, others require oxygen (Whittendury, 1963; Stamer \& Stoyla, 1967). The addition of potential electron acceptor, like fumarate, to the culture medium (Lerche \& Reuter, 1960), might also change the fermentation versatility of some strains. The variable DNA base composition of Lactobacillus brevis and $L$. viridescens suggests that these species are internally heterogeneous. Data taken from $(a)$ Gasser \& Mandel (I968), (b) Rogosa \& Sharpe (I959), (c) Rogosa, Franklin \& Perry (I96I), (d) Sharpe (I955). For nature of antigenic determinants see Sharpe, Davison \& Bradley (1964).

\begin{tabular}{|c|c|c|c|c|c|c|c|c|c|c|}
\hline \multirow[b]{3}{*}{ Species } & \multirow{3}{*}{$\begin{array}{c}\text { Guanine } \\
+ \\
\text { cytosine } \\
\text { content } \\
(a)\end{array}$} & \multirow{3}{*}{$\begin{array}{c}\text { Isomer } \\
\text { of } \\
\text { lactic } \\
\text { acid } \\
\text { (b) }\end{array}$} & & & \multicolumn{6}{|c|}{$\begin{array}{l}\text { Vitamin* } \\
\text { requirement } \\
(b, c)\end{array}$} \\
\hline & & & \multicolumn{2}{|c|}{ Growth at $(b)$} & \multirow{2}{*}{$\begin{array}{l}\text { Arginine } \\
\text { hydrolysis } \\
\quad(b)\end{array}$} & \multirow{2}{*}{$\begin{array}{l}\text { 总. } \\
\text { 总. } \\
\text { 苛. }\end{array}$} & \multirow{2}{*}{ 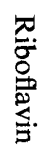 } & \multirow{2}{*}{ 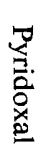 } & \multirow{2}{*}{$\begin{array}{l}\text { T1 } \\
\frac{0}{\bar{\sigma}} \\
\text { : } \\
\text { a. }\end{array}$} & \multirow{2}{*}{$\begin{array}{l}\text { Serological } \\
\text { group } \\
(b, d)\end{array}$} \\
\hline & & & $15^{\circ}$ & $45^{\circ}$ & & & & & & \\
\hline etabacterium & & & & & & & & & & \\
\hline $\begin{array}{l}\text { Lactobacillus } \\
\text { fermenti }\end{array}$ & $53.4 \pm 0.5$ & DL & - & + & + & + & - & - & - & $\mathbf{F}$ \\
\hline L. cellobiosus & $53 \cdot \mathrm{I} \pm 0.8$ & DL & \pm & + & + & + & - & - & - & - \\
\hline L. buchneri & $44 \cdot 8 \pm I \cdot I$ & DL & $\overline{+}$ & - & + & + & \pm & - & - & $\mathbf{E}$ \\
\hline L. brevis & $\begin{array}{l}42 \cdot 7 \pm \mathrm{I} \cdot 5 \\
46 \cdot 4 \pm \mathrm{I} \cdot 0\end{array}$ & DL & + & - & + & + & $\overline{-}$ & - & + & $\mathbf{E}$ \\
\hline L. viridescens & $\left\{\begin{array}{l}42 \cdot 3 \\
35 \cdot 7\end{array}\right.$ & DL & + & - & - & + & + & - & - & - \\
\hline
\end{tabular}

* + requirement; \pm for vitamin requirement and growth means variable result depending on strain; - for serological group means not known.

A second class of enzymes with lactic dehydrogenase activity has been demonstrated in Lactobacillus casei by Mizushima \& Kitahara (1962) and in L. plantarum by Snoswell (1963). These are flavin-linked, NAD-independent enzymes, specific for either $D(-)$ or $L(+)$ lactic acid. The work of Snoswell (1963) suggests that they probably do not operate in the formation of lactic acid from pyruvic acid.

The available information on the lactic dehydrogenases of the lactobacilli indicates that these organisms can contain as many as four different enzymes displaying lactic dehydrogenase activity, two NAD-linked lactic dehydrogenases and two flavin-linked lactic dehydrogenases. We have examined the patterns of distribution and comparative mobilities of lactic dehydrogenases among the different species of the genus Lactobacillus by starch gel electrophoresis. 


\section{METHODS}

Bacterial strains. The sources of the strains examined are listed below. Strains newly isolated by the author were identified according to the criteria proposed by Rogosa \& Sharpe (I959).

NCDO: National Collection of Dairy Organisms, Reading, England. ATCC: American Type Culture Collection, Rockville, Maryland, U.S.A. CNRZ: Centre National de la Recherche Zootechnique, Jouy-en-Josas, France. CIP: Collection de l'Institut Pasteur, Paris, France.

Lactobacillus bulgaricus: NCDO I373; ATCC II842; CNRZ 36; CIP 55I. Strain B IO was received from Dr Sharpe.

Lactobacillus lactis: NCDO 270; NCDO 280; CNRZ 235; CNRZ 237; CNRZ 239; CNRZ 242; CNRZ 245; CNRZ 3II ; CNRZ 9; L I received from Dr Sharpe.

Newly isolated strains: $62 \mathrm{~T}$ from pork meat; $65 \mathrm{~L}$ from urine.

Lactobacillus delbrueckii: ATCC 9649.

Lactobacillus leichmannii: ATCC 4797; ATCC 7830; ATCC 7831; NCDO LEI; NCDO LE7. Strain $63 \mathrm{H}$ was received from Dr Prevot.

Newly isolated strains: $65 \mathrm{AG}, 6 \mathrm{IJ}, 65 \mathrm{~J}$ from urine; 62 $\mathrm{D}$ from the vagina.

Lactobacillus jensenii: newly isolated strains: 62F, 62G, 63 AA, 63A, 63 AN, 60 E from the vagina; strain 66 from a blood clot extracted from an artery.

Lactobacillus acidophilus: NCDO 3; NCDO I; ATCC I9992; ATCC 4356; strains A 2, A4, A5, A6, A8, AII, AI2, AI3, AI4, AI5, AI6, AI7, AI8, AI9, A20, A2I, A22, A 23, A 24, A 25, A26, A 27, A 31 received from Dr Sharpe.

Newly isolated strains: $64 \mathrm{~N}$ from cheese; $64 \mathrm{~F}$ from gastric juice; $65 \mathrm{~K}$ from sputum; HO2/I from saliva; $65 \mathrm{~V}$ and $65 \mathrm{~W}$ from urine; $64 \mathrm{C}$ and $63 \mathrm{E}$ from vagina; $6 \mathrm{I} \mathrm{Z}$ from stool. The origin of strain $\mathrm{X} 82$ is unknown.

Lactobacillus jugurti and L. helveticus: ATCC 7995; NCDO 87; NCDO 99; NCDO 100; NCDO 26I; CNRZ 303, CNRZ 244; CNRZ 32.

Lactobacillus salivarius: ATCC II 742.

Newly isolated strains: 6I AK from faeces and strain $63 \mathrm{AJ}$ from a pharmaceutical preparation of Lactobacillus acidophilus.

Lactobacillus plantarum: NCDO 343; NCDO 773; ATCC 80I4. Strains GC746 and GC 323 were received from Dr Rogosa.

Newly isolated strains: 60 H, 6I A, 6I P, 6I T, 6I D, 6I AF, 6I AL, 6I BB, 6I BH2, 6I BR 3 from faeces; $6 \mathrm{I}$ CA from urine; $63 \mathrm{~J}$ from a dental abcess; 620 from sauerkraut and $64 \mathrm{~L}$ from cheese.

Lactobacillus casei: NCDO I5I; NCDO I52; NCDO I55. Strain 6I BG 3 isolated from stool. Strain B 5I (unknown origin).

Lactobacillus fermenti: ATCC I493I (proposed neotype; Hansen, I968); NCDO 2 I5; CNRZ 236; CNRZ 246 (isolated from natural rennet); CNRZ 233 (isolated from spoiled cheese). Strain oc663 received from Dr Rogosa.

Newly isolated strains: $\mathrm{SAB} / \mathrm{I}, \mathrm{SAC} / \mathrm{I}, \mathrm{AFI}, \mathrm{AF} 3$ from saliva; 6I BN 2 and $6 \mathrm{IK}$ from faeces; 64A from urine. The following strains were also received as Lactobacillus fermenti, but differed significantly from the strains listed above: ATCC 23272; strains f65; f70, f22I received from Dr Raibaud; strain F 5 received from Dr Sharpe as atypical $L$. fermenti.

Lactobacillus cellobiosus: ATCC II739; ATCC I I740. 
Lactobacillus buchneri: NCDO IIO; NCDO III; NCDO I90. Strain oC770 received from Dr Rogosa.

Lactobacillus brevis: ATCC 14869; CNRZ 234; NCDO 23; NCDO 39I; strain I287 received from Dr Buttiaux, and $v 7$ received from Dr Sharpe.

Lactobacillus viridescens: NCDO 403; NCDO S40 (E3), strain FI05 received from Dr Kandler.

The following heterofermentative strains were received without precise identification: $\mathrm{Cuc}_{3}$ isolated from wine, from Dr Kunkee; HO-IOO isolated from intestinal tract of hamster, from Dr Rogosa.

Some heterofermentative strains could not be identified by the criteria of Rogosa \& Sharpe (1959); strains 6I AV, 6I AC, 6I BO3, 65 A, 6I AZ, 6I H, isolated from faeces; strains JOURDAN 2, BARSAC 2, RIOJA II, LA LOUVIERE 2, VI9-3, VRF I, ALSACE 3I, isolated from wine and received from Dr Peynaud; strain $\mathrm{T}$ I I (Lactobacillus pastorianus) received from Dr Sharpe as an unidentified strain.

Conditions of cultivation. Bacteria were grown in a medium containing: Tryptone (Difco), Io g.; yeast extract, 5 g.; Tween 80, I ml.; $\mathrm{MgSO}_{4} \cdot 7 \mathrm{H}_{2} \mathrm{O}, 200 \mathrm{mg}$.; $\mathrm{MnSO}_{4}$. $\mathrm{H}_{2} \mathrm{O}$, $50 \mathrm{mg}$.; $\mathrm{K}_{2} \mathrm{HPO}_{4} .3 \mathrm{H}_{2} \mathrm{O}$, I g.; $\mathrm{KH}_{2} \mathrm{PO}_{4}, 0.8 \mathrm{~g}$.; glucose (autoclaved separately), Io $\mathrm{g}$.; and water to I 1 . This medium supported excellent growth of all species examined except for some strains of Lactobacillus jugurti and L. bulgaricus for which it was supplemented with an enzymic digest of skim milk (10 \% v/v) prepared as follows: reconstituted dry skim milk (I l.) was treated at $37^{\circ}$ for $2 \mathrm{~h}$. with Io $\mathrm{mg}$. of Pronase (Calbiochem), steamed and centrifuged, the pellet being discarded.

Strains of the subgenus Thermobacterium and Lactobacillus fermenti were grown at $37^{\circ}$; all others were grown at $30^{\circ}$. Homofermentative strains were gassed during growth with a mixture of $95 \% \mathrm{~N}_{2}$ and $5 \% \mathrm{CO}_{2}$. Heterofermentative strains were incubated aerobically with gentle shaking.

Preparation of extracts. Organisms were harvested by centrifugation, washed twice in $(\mathrm{Na}, \mathrm{K})$ phosphate buffer (O. I $\mathrm{M}, \mathrm{pH} 7{ }^{\circ}$ ), resuspended in the same buffer ( $150 \mathrm{mg}$. wet wt bacteria/ml.) and subjected to ultrasonic treatment in a MSE $60 \mathrm{~W}$ apparatus for 5 to $20 \mathrm{~min}$. at $0^{\circ}$. The material was centrifuged at $30,000 \mathrm{~g}$ for $30 \mathrm{~min}$. and the supernatant portions were used directly for gel electrophoresis and for enzyme assays.

Conditions for starch gel electrophoresis and for demonstration of lactic dehydrogenase activities. Starch gel electrophoresis was performed by the method of Fine \& Costello (1963) using $25 \times 9 \mathrm{~cm}$. trays, $0.6 \mathrm{~cm}$. deep. A small piece of Whatman $3 \mathrm{MM}$ paper $(5 \times \mathrm{I} \mathrm{mm}$.) was dipped in each extract to be examined and then inserted in the cold gel. Electrophoresis was conducted at $4^{\circ}$ for $\mathrm{I} 6 \mathrm{~h}$. at $200 \mathrm{~V}$ and $25 \mathrm{~mA}$ (for two trays). The gel was then sliced horizontally. Each half was stained specifically to reveal either $\mathrm{D}$ or $\mathrm{L}$ lactic dehydrogenases, by pouring onto its inner surface the following mixture: tris- $\mathrm{HCl}$ buffer $(\mathrm{pH} 8,0 . \mathrm{I} \mathrm{M}), 25 \mathrm{ml}$; ; lithium salt of $\mathrm{D}(-)$ or $\mathrm{L}(+)$ lactic acid ( $2 \mathrm{M})$, I. $5 \mathrm{ml}$; NAD, $72 \mathrm{mg}$.; nitro-blue tetrazolium, $36 \mathrm{mg}$.; phenazine methosulphate, $2 \mathrm{mg}$.

Spots attributable to NAD-independent lactic dehydrogenases were detected by omitting NAD from the staining mixture. The absence of NAD dependence was confirmed by repeating the staining with a mixture in which tris buffer was replaced by $(\mathrm{Na}, \mathrm{K})$ phosphate buffer ( $\mathrm{pH} 5.5, \mathrm{O}^{\circ} \mathrm{I} \mathrm{M}$ ), since at this $\mathrm{pH}$ value NAD-dependent lactic dehydrogenases do not produce spots. The treated gel slices were kept in the dark for 30 to $60 \mathrm{~min}$., while spots developed, and then washed in tap water. 
All the lactic dehydrogenases give very sharp spots (Fig. I) and distances from the origins to the centre of spots could be measured accurately. The actual distance of migration varied from run to run, so the D-lactic dehydrogenase of Lactobacillus acidophilus $\mathrm{NCDO}_{3}$ was used as a control in all experiments and the distance of its migration was assigned an arbitrary value of 10 . The distances of migration of all other enzymes examined are expressed relative to this value. Control experiments showed that the initial position of the sample on the starting line did not significantly affect the speed of migration of the enzyme.

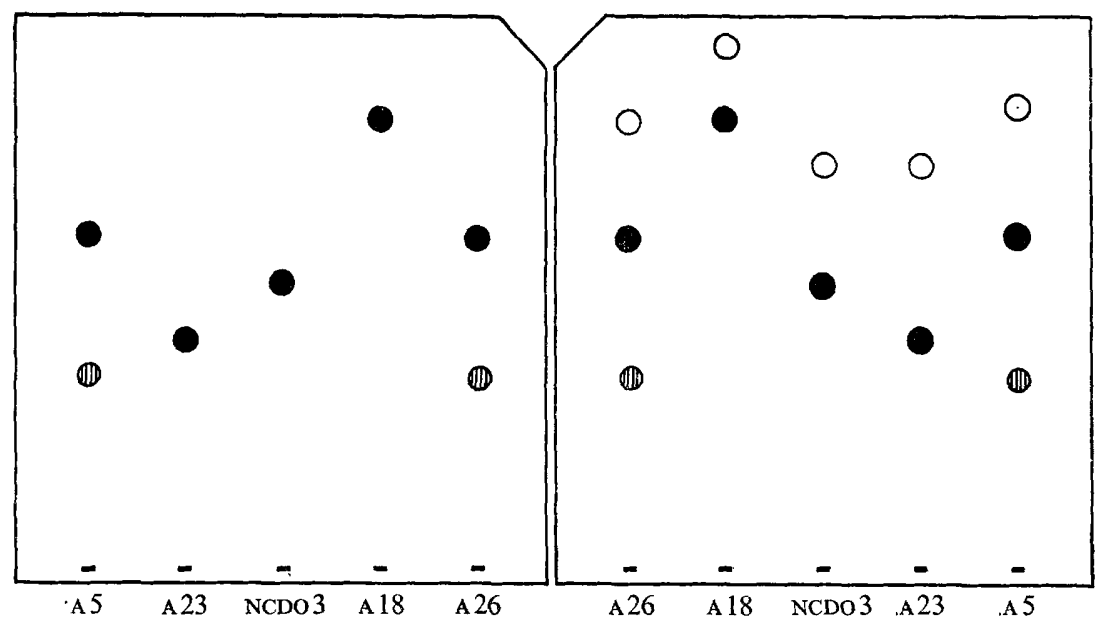

Fig. I. An example of the starch gel electrophoresis of lactic dehydrogenases of several different strains of Lactobacillus acidophilus. After electrophoresis, the gel was sliced and the two halves were incubated with the standard development mixture containing NAD (see Methods). The slice to the right was developed with DL lactate, the slice to the left with $\mathrm{L}(+)$ lactate. Consequently, the spots of L-lactic dehydrogenases are located symmetrically about the median axis, while spots of $\mathrm{D}$-lactic dehydrogenases activity occur only on the right-hand half. The strains employed were all strains of the species $L$. acidophilus; the strain numbers are shown on the diagram. - L-lactic dehydrogenase, NAD-dependent; $\mathrm{O}$, D-lactic dehydrogenase NAD-dependent; $\mathbb{D}$, lactic dehydrogenase, NAD-independent, undetermined specificity.

Assays of NAD-dependent lactic dehydrogenase activity in crude extracts. This activity, in extracts used for electrophoresis experiments, was routinely assayed at $25^{\circ}$ by determining the reduction of NAD (measured at $340 \mathrm{~nm}$.) in I ml. of a mixture containing: tris- $\mathrm{HCl}$ buffer $(\mathrm{pH} \mathrm{8.0)}, 200 \mu$ moles; the lithium salt of either $\mathrm{D}(-)$ or $\mathrm{L}(+)$ lactic acid, I00 $\mu$ moles; NAD, $2 \mu$ moles. The reaction was initiated by addition of a sufficient amount of extract to give an increased extinction of about 0.050 optical density unit during the first minute. The unit of enzyme is defined as the amount which reduced I $\mu$ mole of $\mathrm{NAD} / \mathrm{min} . / \mathrm{ml}$. under these conditions; activity in crude extracts ranged from 0.3 to 5 units $/ \mathrm{mg}$. protein. Protein was determined by the method of Lowry, Rosebrough, Farr \& Randall (195I).

Synthesis of $L(+)$ lactate in vitro. To show the formation of $\mathrm{L}(+)$ lactate from pyruvate and $\mathrm{NADH}$ as substrates, a series of tubes was prepared containing: crude extract (I mg. protein) of the required bacterium, $\mathrm{Na}$ pyruvate $(50 \mu \mathrm{moles}), \mathrm{NADH}$ ( 4 to $40 \mu$ moles) and potassium phosphate buffer (0.1 $\mathrm{M}, \mathrm{pH} 6$ ) in a total volume of 
I $\mathrm{ml}$. After incubation at $37^{\circ}$ for $30 \mathrm{~min}$., the tubes were plunged into a boiling water bath for 3 min., cooled and then centrifuged. The amount of $L(+)$ lactic acid in the supernatants was measured by the method of Appleby \& Morton (I959), using the cytochrome-linked L-lactic dehydrogenase of yeast (Worthington Biochemical Corp.)

\section{RESULTS}

The number of lactic dehydrogenases detected and their electrophoretic mobilities are recorded for homofermentative species in Table 4 and for heterofermentative species in Table 5 .

For the most part, each species showed a high degree of uniformity with respect to its complement of lactic dehydrogenases. Furthermore, species (or species-groups) could be distinguished from one another by the nature, the number and the distances of migration (with their small standard deviation) of their respective lactic dehydrogenases (Fig. 2, 3). The greatest variability was shown by the NAD-dependent D-lactic dehydrogenases of the strains of group Ib of Lactobacillus acidophilus, which had electrophoretic mobilities ranging from I I to 15 (Table 4 ).

\section{Correlation between the optical configuration of lactic acid produced and the stereospecificity of NAD-dependent lactic dehydrogenases}

The optical configuration of the lactic acid produced by the different Lactobacillus species is shown in Tables 2 and 3 . In general, this property correlated excellently with the number and stereospecificity of the NAD-dependent lactic dehydrogenases revealed after starch gel electrophoresis of crude extracts (Tables 4, 5; Fig. 2, 3). Species which produced either $\mathrm{D}(-)$ or $\mathrm{L}(+)$ lactic acid as fermentative end-product characteristically possessed a single NAD-dependent lactic dehydrogenase with the corresponding stereospecificity. Species which produced racemic lactic acid as a fermentative end-product characteristically possessed two NAD-dependent lactic dehydrogenases of different stereospecificities. As a general rule, each species contains only one NAD-dependent enzyme specific for a given stereoisomer of lactic acid. However, a few strains of heterofermentative lactobacilli apparently contained three distinct NAD-dependent enzymes, specific for the $\mathrm{L}(+)$ isomer of lactic acid (Table 5).

Discrepancies between the configuration of lactic acid formed and the specificity of the NAD-dependent enzymes demonstrable in crude extracts were encountered in Lactobacillus fermenti, L. jugurti and L. casei. The two former species produce racemic lactic acid, while the latter produces $L(+)$ lactic acid. In none of these three species was an NAD-dependent L-lactic dehydrogenase demonstrated either by direct spectrophotometric assays on extracts or by staining after starch gel electrophoresis. The failure to demonstrate an NAD-dependent L-lactic dehydrogenase in these species might be because the assay methods were inadequate. Our assays depended on the oxidation of lactic acid to pyruvic acid, even though under physiological conditions these enzymes catalyse the reverse reaction, the reduction of pyruvic to lactic acid. The use of lactic acid as the substrate was convenient since it permitted a simple determination of stereospecificity. With pyruvic acid and NADH as substrates, crude extracts of all these species formed $\mathrm{L}(+)$ lactic acid (see Methods p. 230). For example, Lactobacillus jugurti formed 3 to $32 \mu$ moles $/ \mathrm{ml}$. of $\mathrm{L}(+)$ lactic acid in the supernatant from the incubation mixture. No appreciable amount of $\mathrm{L}(+)$ lactic acid was 
Table 4. Electrophoretic mobilities of lactic dehydrogenases of homofermentative Lactobacillus species

The mobilities are calculated relative to an arbitrary value of 10 assigned to the NAD-dependent D-lactic dehydrogenase of Lactobacillus acidophilus NCDO 3.

Distance of migration of lactic dehydrogenases (mean value and standard deviation)

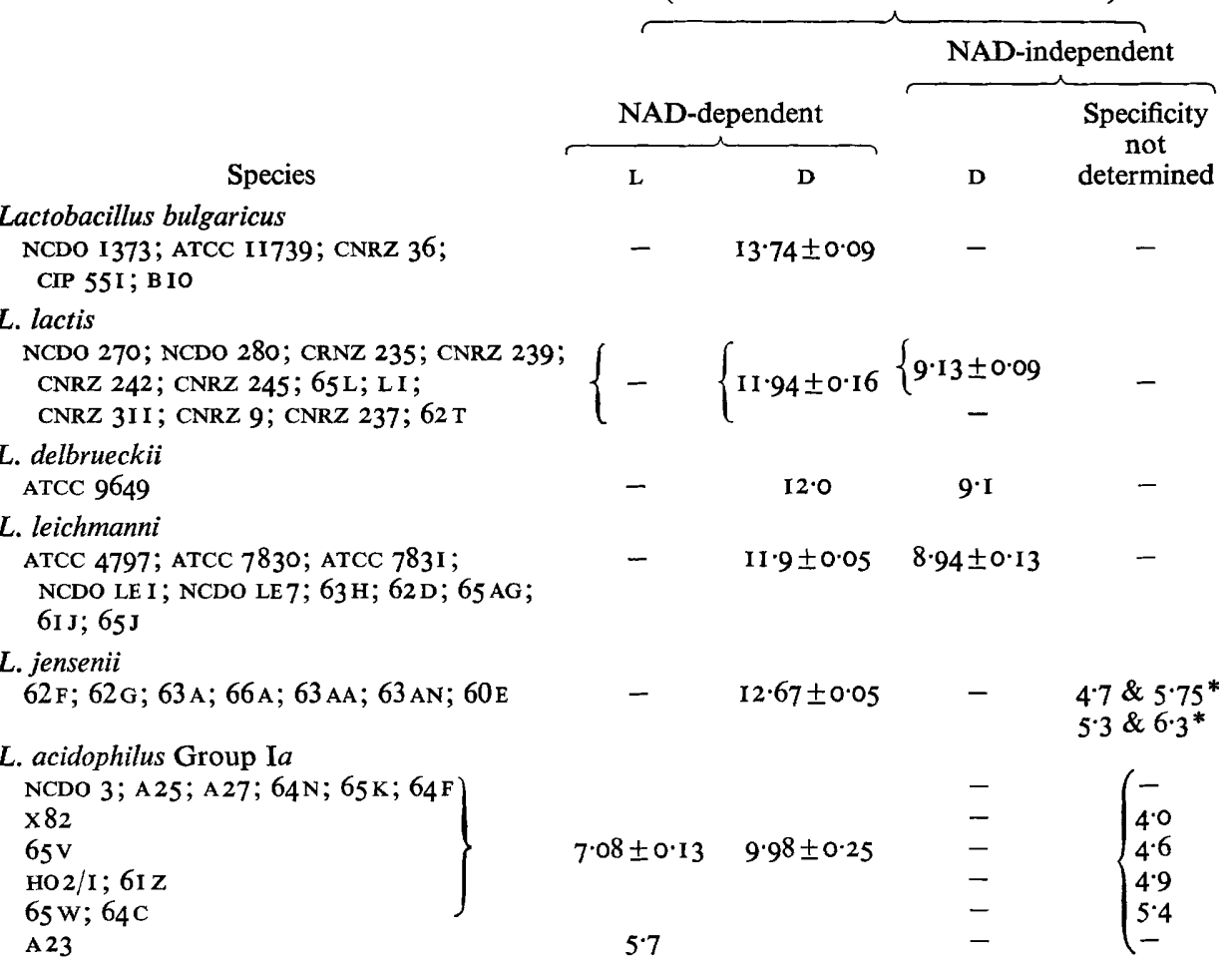

L. acidophilus Group I $b$

$\left.\begin{array}{l}\text { ATCC 19992 } \\ \text { A I } 7 \\ \text { A } 24 \\ 63 \text { E } \\ \text { A } 21 \\ \text { A I9 } \\ \text { A 20; A 22 } \\ \text { A } 14\end{array}\right\}$

$6.91 \pm 0.19 \quad\left\{\begin{array}{l}11 \cdot 0 \\ 11 \cdot 9 \\ 12 \cdot 4 \\ 12.8 \\ 12.9 \\ 13.0 \\ 13.4 \\ 15.0\end{array}\right.$

L. acidophilus Group II

$\left.\begin{array}{l}\text { A I } 5 \\ \text { A } 5 \text {; A } 26 \\ \text { A I } 3 \\ \text { A } 4 \text {; A II } \\ \text { A I } 2\end{array}\right\}$

$8 \cdot 3 \pm 0.05 \quad I I \cdot 2 I \pm 0.4 I \quad \begin{cases}- & I \cdot I \\ - & 3 \cdot 25 \\ - & 2 \cdot 8 \\ 6 \cdot 35 & 2 \cdot 95 \\ 6 \cdot 3 & 4 \cdot 0\end{cases}$

L. acidophilus Group III

NCDO I; ATCC 4356; A 2; A 6; A 8; A I6; $11 \cdot 23 \pm 0.14 \quad 12 \cdot 97 \pm 0.13$ A I 8; A 3 I

L. jugurti-L. helveticus

NCDO 26I; NCDO 99; NCDO 87; NCDO IOO; 9.33 $\pm 0.05 \quad 7.65 \pm 0.26$

ATCC 7995; CNRZ 303; CNRZ 244; CNRZ 32 
Table 4 (cont.)

Distance of migration of lactic dehydrogenases (mean value and standard deviation)

Species

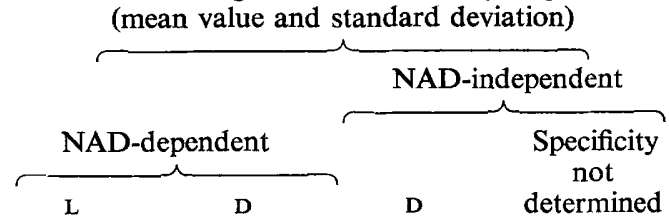

L. plantarum

NCDO 343; NCDO 773; ATCC 8014; GC 746; II $32 \pm 0.02 \quad$ I $2 \cdot 36 \pm 0.09$

$6 \mathrm{OH} ; 6 \mathrm{I} \mathrm{A} ; 6 \mathrm{IP} ; 6 \mathrm{I} \mathrm{T} ; 6 \mathrm{I} \mathrm{AF} ; 6 \mathrm{I} \mathrm{AL} ; 6 \mathrm{I} \mathrm{BB}$;

$6 \mathrm{I} \mathrm{BH} 2 ; 6 \mathrm{I} \mathrm{BR} 3 ; 6 \mathrm{I} \mathrm{CA} ; 63 \mathrm{~J} ; 62 \mathrm{O} ; 64 \mathrm{~L}$; GC $323 ; 6$ I D

$9 \cdot 9$

$5 \cdot 6$

L. salivarius

ATCC II $742 ; 6 \mathrm{I} \mathrm{AK} ; 63 \mathrm{AJ}$

L. casei

NCDO I5I; NCDO I 52 ; NCDO I $55 ; 6$ I BG;

B 5I

* Two separated spots.

-, Means enzyme not detected after electrophoresis (no visible spot). See text for comments regarding NAD-dependent L-lactic dehydrogenase of $L$. casei.

detected in controls from which either $\mathrm{Na}$ pyruvate or crude extracts was omitted; the relationship between the amount of NADH provided and the amount of $L(+)$ lactic acid produced was linear but not stoichiometric, probably because an NADdependent D-lactic dehydrogenase, as well as weak activity of an NADH oxidase was present in the crude extracts.

The formation of $\mathrm{L}(+)$ lactic acid from pyruvic acid in the presence of NADH might reflect the coupled activity of a lactic racemase and an NAD-dependent D-lactic dehydrogenase in the specific cases of Lactobacillus fermenti and L. jugurti, both of which possess readily demonstrable D-lactic dehydrogenase activity. However, attempts to demonstrate by the procedure of Dennis (I962) the formation of $L(+)$ lactic acid from $\mathrm{D}(-)$ lactic acid in the absence of NAD by extracts of $L$. fermenti and $L$. jugurti gave completely negative results. $L$. jugurti, $L$. fermenti and $L$. case $i$ therefore probably produced $\mathrm{L}(+)$ lactic acid by means of an NAD-dependent L-lactic dehydrogenase which catalyses a virtually irreversible reduction of pyruvic acid. Several modifications of the standard procedure for staining gels were tested in an attempt to demonstrate spots corresponding to the activity of L-lactic dehydrogenases in these three species. With L. jugurti, if the $\mathrm{pH}$ of the development mixture was lowered to 6.0 (in $0.1 \mathrm{M}$-phosphate buffer), a spot corresponding to the activity of L-lactic dehydrogenase appeared, although its development was slow. However, all attempts to demonstrate spots corresponding to activity of L-lactic dehydrogenase after starch gel electrophoresis of extracts of $L$. casei and $L$. fermenti failed. In the specific case of $L$. casei, these results confirm those of Mizushima \& Kitahara (I962), who failed to detect any L-lactic dehydrogenase activity at $\mathrm{pH} 7 \cdot 0$. Mizushima found a very low D-lactic dehydrogenase activity in this species. We have confirmed the presence of this enzyme in extracts of $L$. casei by spectrophotometric assay, but have not detected a corresponding spot after electrophoresis, probably because the activity is so low. 
The distribution of NAD-independent lactic dehydrogenases

Six groups among the homofermentative lactobacilli contain NAD-independent lactic dehydrogenases, which could be distinguished from the NAD-dependent enzymes after electrophoresis of extracts because they gave spots even if NAD was omitted from the development mixture.

Table 5. Electrophoretic mobilities of lactic dehydrogenases of heterofermentative Lactobacillus species

For explanation see legend of Table 4. No NAD-independent lactic dehydrogenases were found.

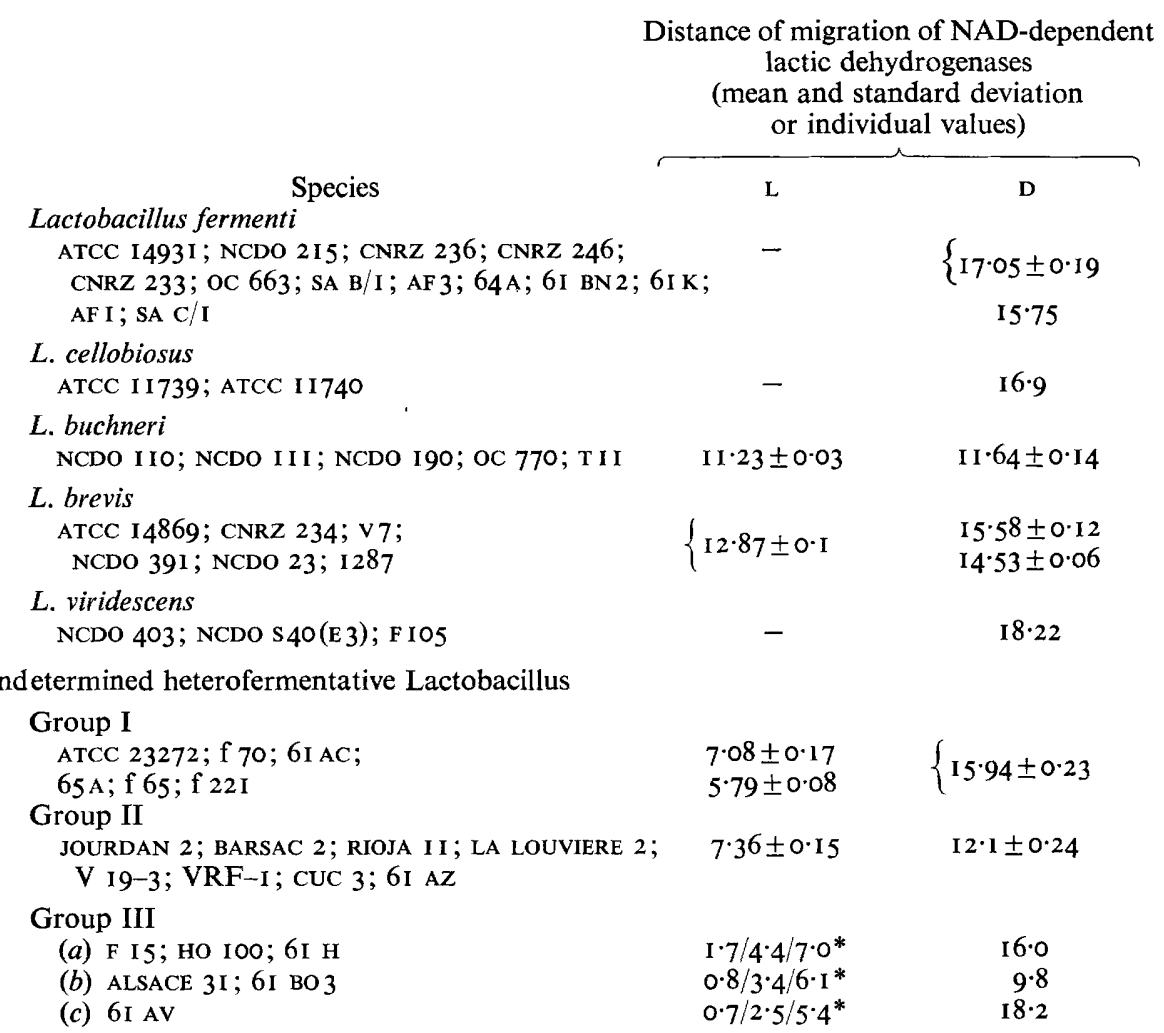

* Three separated spots.

-, Means enzyme not detected after electrophoresis (no visible spot). See text for comments regarding NAD-dependent L-lactic dehydrogenase of $L$. fermenti.

The single strain of Lactobacillus delbrueckii examined, all strains of L. leichmannii, and 8 of the 12 strains of $L$. lactis contain substantial levels of activity of an NADindependent lactic dehydrogenase which is specific for the $D(-)$ isomer. The migration of these enzymes on starch gels was characteristic and identical for all three species (Table 4).

Strains of Lactobacillus jensenii also contained considerable activities of NADindependent lactic dehydrogenase. Two spots appeared after gel electrophoresis; 
their migrations were almost constant for the strains of this species, and different from those of the enzymes in L. delbrueckii, L. leichmannii and L. lactis. Furthermore, the enzymes of $L$. jensenii reacted with either $\mathrm{D}(-)$ or $\mathrm{L}(+)$ lactic acid as substrate. Since enzymic assay showed that all samples of $D(-)$ lactic acid available contained 4 to $6 \%$ of the $\mathrm{L}(+)$ isomer, this result could reflect the steric impurity of the substrate used in the development mixture. However, even when the minimal concentration of lactic acid necessary to yield a spot was used in the development mixture, the intensities of the spots obtained were the same with both the $\mathrm{D}(-)$ and the $\mathrm{L}(+)$ isomers.

In Lactobacillus acidophilus, only a few strains contained NAD-independent lactic dehydrogenases, and the activity of these enzymes was relatively low. Their migration varied from strain to strain. Thirteen of the tested strains yielded one spot with either $\mathrm{D}(-)$ or $\mathrm{L}(+)$ lactic acid. Three of these strains yielded an additional spot, specific for the $\mathrm{D}(-)$ isomer. Fifteen strains of $L$. acidophilus contained no detectable NADindependent lactic dehydrogenase activity.

In Lactobacillus plantarum, only 2 strains out of 19 showed NAD-independent lactic dehydrogenases, specific for $\mathrm{D}(-)$ lactic acid. These two strains also differed from other strains of this species in the mobility of their NAD-dependent L-lactic dehydrogenases.

The method of development which we used may not detect all the NAD-independent lactic dehydrogenases present. For example, Snoswell (1963) described flavin-linked D- and L-lactic dehydrogenases of Lactobacillus plantarum ATCC 8014 which did not reduce phenazine methosulphate $\left(E_{0}^{\prime}=+0.080 \mathrm{~V}\right)$ but reduced only dyes with $E_{0}^{\prime}$ greater than $+0^{\circ} \mathrm{I}$ V. Probably for the same reason, the flavin-linked D- and L-lactic dehydrogenases of $L$. casei described by Mizushima \& Kitahara (I962) were not detected by us in extracts of this species.

\section{The effect of conditions of growth on the formation of lactic dehydrogenases}

The possibility that the nature of the energy source might influence the type of lactic dehydrogenases produced was examined for two species, Lactobacillus buchneri and L. plantarum. Buyze (1955) and later Stamer \& Stoyla (1967) showed that L. brevis requires $\mathrm{O}_{2}$ when grown with glucose as an energy source, but not when grown with fructose or pentoses. We have found the same behaviour in a second heterofermentative species, L. buchneri. Lactobacillus buchneri NCDO I I 1 and NCDO I I I were grown with fructose and arabinose under both aerobic and anaerobic conditions, and with glucose under aerobic conditions. Extracts of all cultures were prepared and subjected to electrophoresis. Neither the number nor the electrophoretic mobility of the lactic dehydrogenases was affected by growth conditions.

Lactobacillus plantarum uses different pathways for the fermentation of glucose and pentoses. Although the terminal steps (conversion of triose-phosphate to lactic acid) are common to both pathways, it appeared possible that they might be catalysed by different sets of isofunctional enzymes. Lactobacillus plantarum NCDO 343 and 6I were grown with glucose, fructose, arabinose or ribose and extracts of the cells were prepared. All extracts contained the same complement of lactic dehydrogenases with the same electrophoretic mobilities. 


\section{DISCUSSION}

The value of lactic dehydrogenases as taxonomic markers among the lactobacilli

The multiplicity of lactic dehydrogenases among the lactobacilli makes these enzymes particularly useful as taxonomic markers. As shown in Tables 4 and 5, some species are characterized by a particular constellation of lactic dehydrogenases, differing from one another in stereospecificity and cofactor requirements, and possessing nearly identical electrophoretic mobilities in all strains of the species examined. Examples are Lactobacillus jugurti and L. helveticus (which have identical patterns), $L$. bulgaricus, $L$. plantarum and $L$. jensenii. In some cases, a more complex lactic dehydrogenase pattern is evident in the strains assigned to a single species. The most striking example is L. acidophilus, the strains of which can be subdivided into three major groups in terms of the electrophoretic mobilities of their NAD-dependent D- and L-lactic dehydrogenases.

The intraspecific constancy of the electrophoretic mobility of the enzymes studied is perhaps surprising, since a single amino acid substitution in a protein can greatly modify its rate of migration (Barrow \& Margoliash, I966). In the coliform bacteria Bowman, Brubaker, Frischer \& Carson (1967) have shown considerable variation in the electrophoretic mobility of glucose-6-phosphate dehydrogenase and 6-phosphogluconate dehydrogenase even among the strains of a single species. A few examples of such variability have emerged from the present work, notably with respect to the D-lactic dehydrogenase of Lactobacillus acidophilus strains which belong to Group Ib. It is, however, striking that the L-lactic dehydrogenase of the same group of strains shows a completely constant electrophoretic mobility. Hence in this group the electrophoretic mobility of the L-specific enzyme is a useful taxonomic character, whereas that of the D-specific enzyme is not. The high degree of constancy of the electrophoretic mobility of the lactic dehydrogenases in most Lactobacillus species suggests that these proteins remain stable during evolution.

The fact that a given type of lactic dehydrogenase has the same electrophoretic mobility in two strains does not necessarily indicate that the enzymes of the two strains are closely similar in their primary structure. However, when the strains show substantial overall phenotypic similarities and a closely similar mean DNA base composition, the probability that the enzymes are homologous proteins becomes considerably greater.

\section{Utility of the method for species differentiation}

The electrophoretic mobilities of lactic dehydrogenases provides very useful characters for the specific identification of newly isolated strains, particularly in cases where the usual differential characters listed in Tables 2 and 3 give ambiguous results. In an accompanying paper, Gasser, Mandel \& Rogosa (1970) have shown that Lactobacillus jensenii and L. leichmannii are indistinguishable by these characters, whereas the electrophoretic mobilities of their lactic dehydrogenases permits their differentiation.

Three other problems of differential specific diagnosis among lactobacilli are often encountered.

I. Lactobacillus acidophilus and L. leichmannii. Rogosa \& Sharpe (1959) noted that strains of $L$. leichmannii that do not hydrolyse arginine can easily be confused 
with L. acidophilus (see Table 2). The lack of lactose or galactose fermentation by L. leichmannii is not a reliable character, since these substrates are in fact fermented by $L$. leichmannii when conditions are strictly anaerobic (M. Rogosa, personal

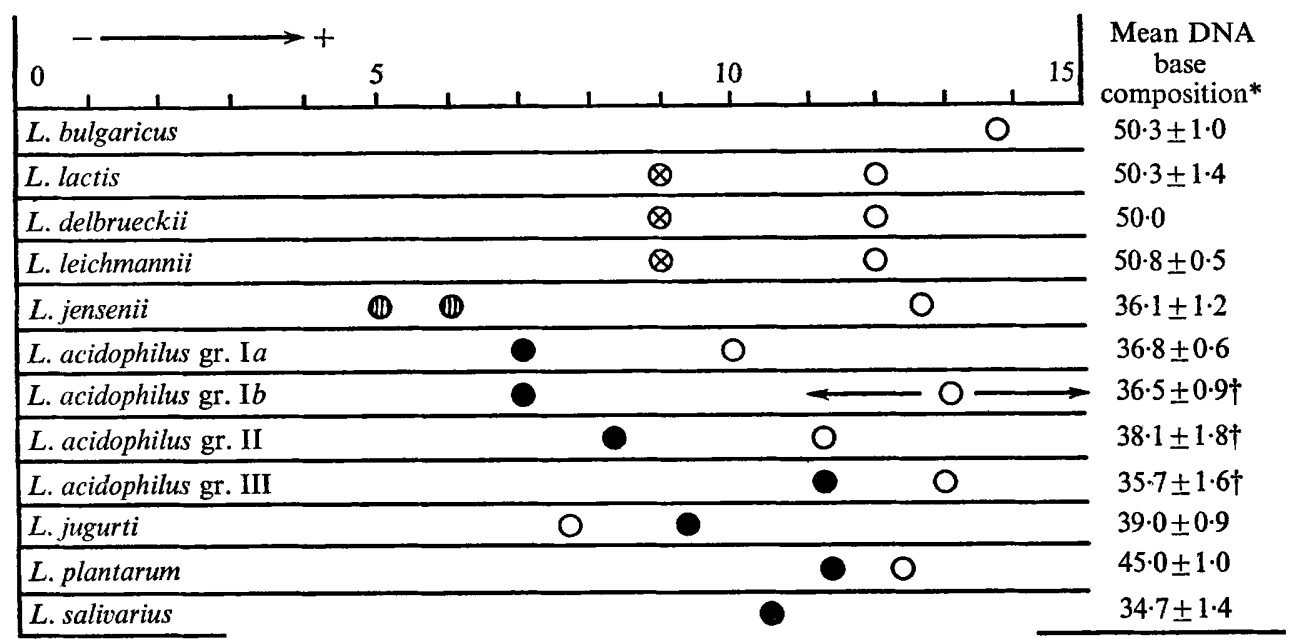

Fig. 2. Relative positions after starch gel electrophoresis of the main spots of lactic dehydrogenases of homofermentative Lactobacillus species. O, L-lactic dehydrogenase, NAD-dependent; $O$, D-lactic dehydrogenase, NAD-dependent; $\otimes$, D-lactic dehydrogenase, NAD-independent; $\mathbb{D}$, lactic dehydrogenase, NAD-independent, undetermined specificity.

* Data from Gasser \& Mandel, 1968.

$\dagger$ Data from M. Mandel (personal communication).

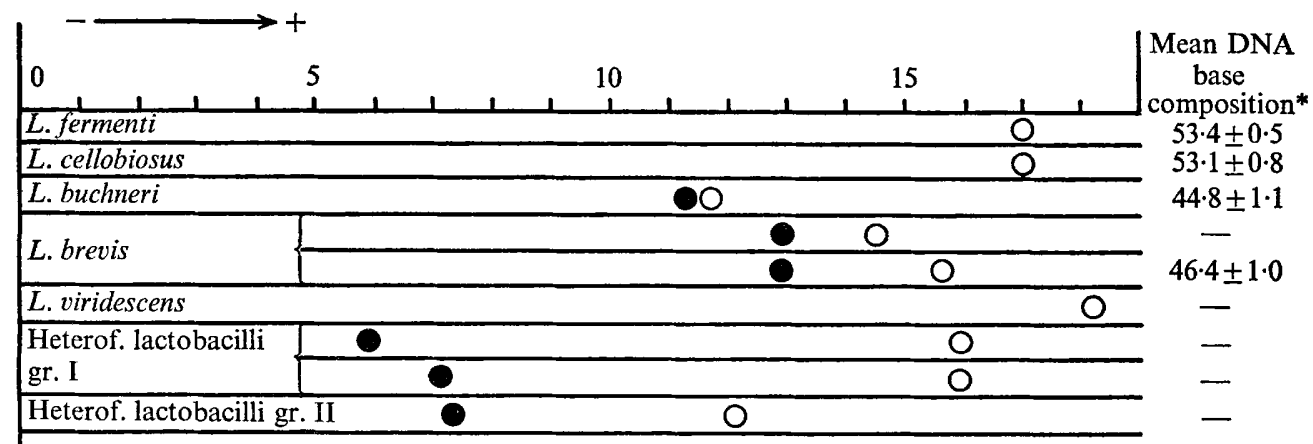

Fig. 3. Relative positions after starch gel electrophoresis of the main spots of lactic dehydrogenases of heterofermentative Lactobacillus species. 0 , L-lactic dehydrogenase, NAD-dependent; $O$, D-lactic dehydrogenase, NAD-dependent.

* Data taken from Gasser \& Mandel, I968.

communication). The clear-cut differences in the electrophoretic mobilities of their lactic dehydrogenases are thus particularly useful for their differentiation (Fig. 2). For example, four arginine negative strains $(64 \mathrm{~F}, 65 \mathrm{~V}, 64 \mathrm{C}$ and $\mathrm{x} 82)$ which had been previously identified as $L$. leichmannii on the basis of the lack of fermentation of lactose and/or galactose were found to be strains of $L$, acidophilus on the basis 
of the electrophoretic pattern of their lactic dehydrogenase; they were variants which did not ferment lactose or galactose.

2. Lactobacillus jugurti and L. bulgaricus. The phenotypic differentiation of these two species (Table 2) is frequently difficult, although the distinctions of the two species was clearly established by De Man (I960) and subsequently confirmed by the large difference between their mean DNA base compositions (Gasser \& Sebald, I966; Gasser \& Mandel, I968). The migration pattern of their lactic dehydrogenases permits easy differentiation (Fig. 2).

3. Lactobacillus casei and $L$. plantarum. The electrophoretic mobility of lactic dehydrogenases permits a sharp differentiation between these two species. No intermediate patterns of migration of lactic dehydrogenase were encountered, although the lack of constancy of the main phenotypic characters used to differentiate $L$. casei from $L$. plantarum (see Table 2 ) had suggested that intermediate strains might exist.

This investigation was supported in part by U.S. Public Health Service grant AI-I808 from the National Institute of Allergy and Infectious Diseases, and in part by National Science Foundation grant GB-4I I2. The travel expenses of the author were defrayed by a Fulbright grant, P.L. 87256.

I wish to thank Dr Allan Wilson for helpful discussions during this study, and Dr R. Buttiaux, Dr O. Kandler, Dr N. O. Kaplan, Dr R. Kunkee, Dr M. Peynaud, Dr A. R. Prevot, Dr M. Raibaud, Dr M. Rogosa and Dr M. E. Sharpe for providing some of the cultures used in this work. My special thanks go to Dr Roger Y. Stanier and Dr Michael Doudoroff for their interest, advice and assistance throughout the course of this work.

\section{REFERENCES}

Appleby, C. A. \& Morton, R. K. (I959). Lactic dehydrogenase and cytochrome $b_{2}$ of baker's yeast. Purification and crystallization. Biochemical Journal 7I, 492-499.

Barrow, G. \& Margoliash, E. (1966). Electrophoretic behaviour of mammalian-type cytochromes $c$. Journal of Biological Chemistry 24I, I473-r477.

Bowman, J. E., Brubaker, R. R., Frischer, H. \& Carson, P. E. (1967). Characterization of enterobacteria by starch gel electrophoresis of glucose-6-phosphate dehydrogenase and phosphogluconate dehydrogenase. Journal of Bacteriology 94, 544-55I.

BuYZE, G. (1955). De koolhydraatstofwisseling van Lactobacillus brevis (The Carbohydrate Metabolism of Lactobacillus brevis). Thesis, Utrecht, The Netherlands.

Buyze, G., VAN den Hamer, C. J. A. \& DE HAan, P. G. (1957). Correlation between hexose-monophosphate shunt, glycolytic system and fermentation-type in lactobacilli. Antonie van Leeuwenhoek 23, 345-350.

DENNIS, D. (1962). Lactic acid racemase from Clostridium butyricum. In Methods in Enzymology, vol. V, pp. 430-432. Edited by S. P. Colowick \& N. O. Kaplan. New York \& London: Academic Press.

Dennis, D. \& KaPlan, N. O. (1960). D and L lactic acid dehydrogenases in Lactobacillus plantarum. Journal of Biological Chemistry 235, 810-8 8 .

De Man, J. C. (1960). Lactobacillus bulgaricus (Luerssen et Kühn) Holland. Antonie van Leeuwenhoek 26, 77-80.

Fine, I. H. \& Costello, L. A. (1963). The use of starch electrophoresis in dehydrogenase studies. In Methods in Enzymology, vol. VI, pp. 958-972. Edited by S. P. Colowick \& N. O. Kaplan. New York and London: Academic Press.

Gasser, F. \& MANDel, M. (I968). Deoxyribonucleic acid composition of the genus Lactobacillus. Journal of Bacteriology 96, 580-588.

Gasser, F., Mandel, M. \& Rogosa, M. (1970). Lactobacillus jensenii sp.nov., a new representative of the subgenus Thermobacterium. Journal of General Microbiology 62, 219-222. 
Gasser, F. \& Sebald, M. (1966). Composition en bases nucléiques des bactéries du genre Lactobacillus, Annales de l'Institut Pasteur, Paris 110, 261-275.

Hansen, P. A. (1968). Type of Lactobacillus species. A Report by the Taxonomic Subcommittee on Lactobacilli and Closely Related Organisms. (A Subcommittee of the International Committee on Nomenclature of Bacteria of the International Association of Microbiological Societies). Rockville, Maryland: The American Type Culture Collection.

KLUYver, A. J. (1935). Die bakteriellen Zuchervergärungen. Ergebnisse der Enzymforschung 4, 230-273.

KNox, K. W. (1963). Isolation of group specific products from Lactobacillus casei and L. casei var. rhamnosus. Journal of General Microbiology 3r, 59-72.

LERCHE, M. \& ReUTER, G. (I960). Beitrag zur Methodik der Isolierung und Differenzierung von aerob wachsenden 'Laktobazillen' (Genus 'Lactobacillus Beijerinck'). Zentralblatt für Bakteriologie, Abt I, Originale r79, 354-370.

Lowry, O. H., Rosebrough, N. J., Farr, A. L. \& Randall, R. J. (I95I). Protein measurement with the Folin phenol reagent. Journal of Biological Chemistry I93, 265-275.

Mizushima, S. \& Kitahara, K. (1962). Purification and properties of lactic dehydrogenase of Lactobacillus casei. Journal of General and Applied Microbiology, Tokyo 8, 130-14I.

Orla Jensen, S. (1919). The Lactic Acid Bacteria. Edited by Andr. Fred. Copenhagen: Host \& Son.

Rogosa, M., Franklin, J. G. \& Perry, K. D. (I96I). Correlation of the vitamin requirements with cultural and biochemical characters of Lactobacillus spp. Journal of General Microbiology 26 473-482.

Rogosa, M. \& Sharpe, M. E. (1959). An approach to the classification of the lactobacilli. Journal of Applied Bacteriology 22, 329-340.

SHARPE, M. E. (I955). A serological classification of lactobacilli. Journal of General Microbiology I2, $107-122$.

Sharpe, M. E., Davison, A. L. \& Baddiley, J. (1964). Teichoic acids and group antigens in lactobacilli. Journal of General Microbiology 34, 333-340.

SNoswell, A. M. (1963). Oxidized nicotinamide-adenine dinucleotide independent lactate dehydrogenases of Lactobacillus arabinosus 17.5. Biochimica et Biophysica Acta 77, 7-19.

STAMER, J. R. \& Stoyla, B. O. (1967). Growth response of Lactobacillus brevis to aeration and organic catalysts. Applied Microbiology 15, 1025-1030.

WhITENBURY, R. (1963). The use of soft agar in the study of conditions affecting the utilization of fermentable substrates by lactic acid bacteria. Journal of General Microbiology 32, 375-384.

Wood, W. A. (196I). Fermentation of carbohydrates and related compounds. In The Bacteria, vol. II, ch. 2. Edited by I. C. Gunsalus \& R. Y. Stanier. New York and London: Academic Press. 